
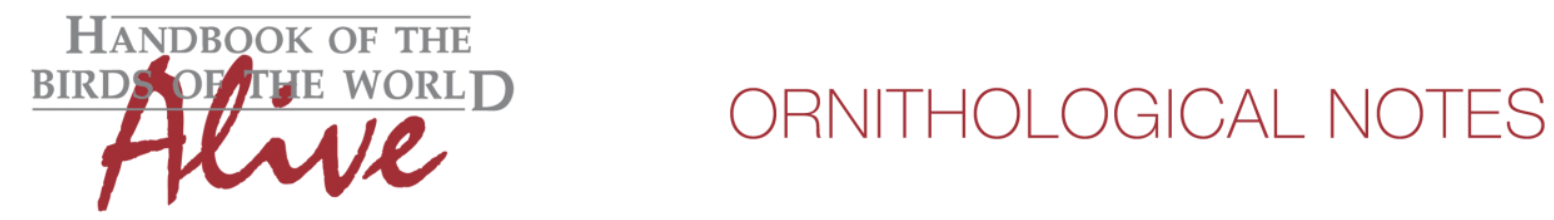

\title{
Notes on the vocalizations of Great Egret (Ardea alba)
}

\author{
Peter Boesman
}

In the following text, I briefly analyze and compare the voice of the different races of Great Egret (Ardea alba). I also try to quantify the extent of any vocal differences using the criteria proposed by Tobias et al. (2010), as a basis for taxonomic review. I have made use of sound recordings available online at Xeno Canto (XC).

Great Egret Ardea alba is a cosmopolitan species of which four taxa are recognized: nominate in the Palearctic region, modesta in the Orient and Australasia, melanorhynchos in the Afrotropics and egretta in the New World (for more detailed ranges, see Martínez-Vilalta et al. 2017).

Taxonomy has been discussed in the literature over the years, with a species-level split of modesta being recommended by some authorities (Kushlan \& Hancock 2005, Christidis \& Boles 2008, IOC 1.62.7), but following a summary paper (Pratt 2011) most commentators have again elected in favour of caution and have treated the four taxa as a single species. Pratt in fact concluded that existing evidence could support only two reasonable options (either lump all four taxa or elevate egretta to species rank) but that future genetic studies might result in the acceptance of more biological species. While taxonomic discussion has focused mainly on morphology, courtship behaviour and genetic data, voice has apparently never been included in the discussion. This is hardly surprising, as vocabulary in large herons is rather limited and calls of most species sound superficially similar, thus are seemingly of little use for taxonomic analysis. Nevertheless, in any given locality, sympatric herons can often be distinguished by call. It seems worthwhile therefore to check for vocal differences among the allopatric taxa of Great Egret.

Based on available recordings away from their breeding colonies, the vocabulary of Great Egret seemingly consists of the following calls (most recordists typically made sound recordings of birds either flushed, alarmed by the recordist's presence, in normal flight or interacting with other birds):

* The rattle call: a gurgling vibrating call, easily distinguished on sonogram by its regular discrete wellspaced notes (c. 15 notes/second)

* The "rraah" call: a raucous call without any clear vibration, in sonograms discrete notes are hardly discernible as they are uttered at a much higher pace than the previous call (c. 50 notes/second or more)

* The nasal call: similar to previous call, but with a distinctly nasal quality. In sonograms, no discrete notes are discernible and clear frequency bands are visible. In fact, this and the previous call show a continuum, and intermediate calls might be assigned to either category.

* The short "kok" call: a much shorter call ( $<0.2$ second), which may be just a short variant of previous calls.

I have categorized the 164 available XC recordings into these call types with the following results (excluding juvenile calls, counting for every call type in every recording and adding a few sonograms as examples): 


\section{HANDBOOK OF THE \\ Alve}

\section{ORNITHOLOGICAL NOTES}

\section{Nominate}

Rattle call $(n=27)$
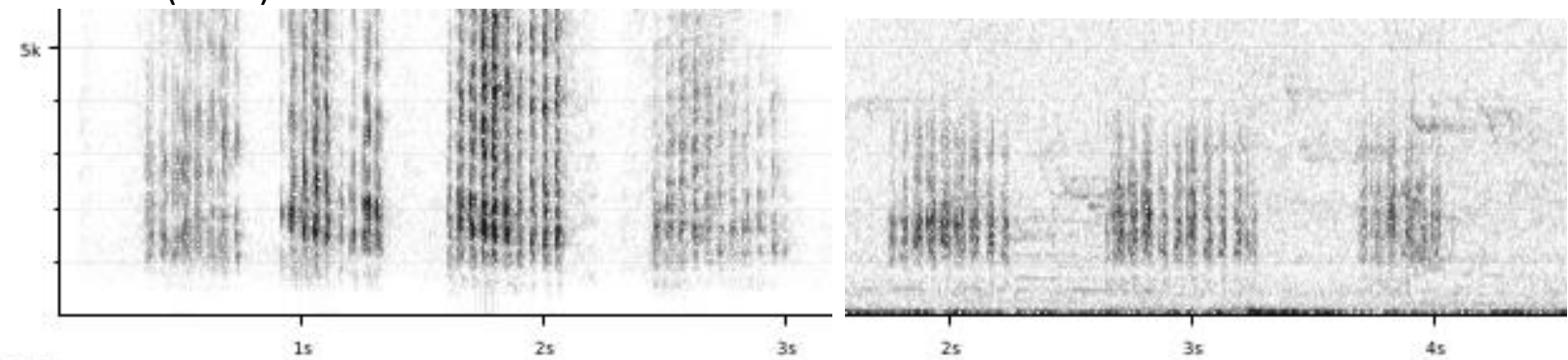

(sonograms from XC285221, Belgium, J.Simar; XC187098, Poland, J. Matusiak)

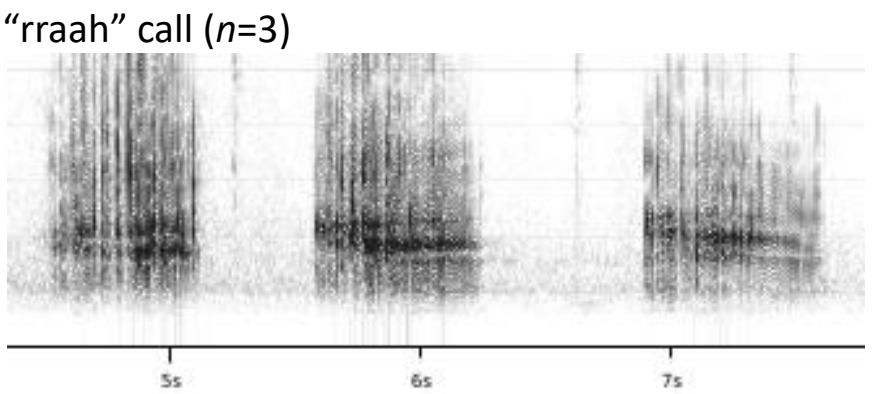

(sonogram from XC144937, Italy, M. Dragonetti)

Nasal call $(n=1)$

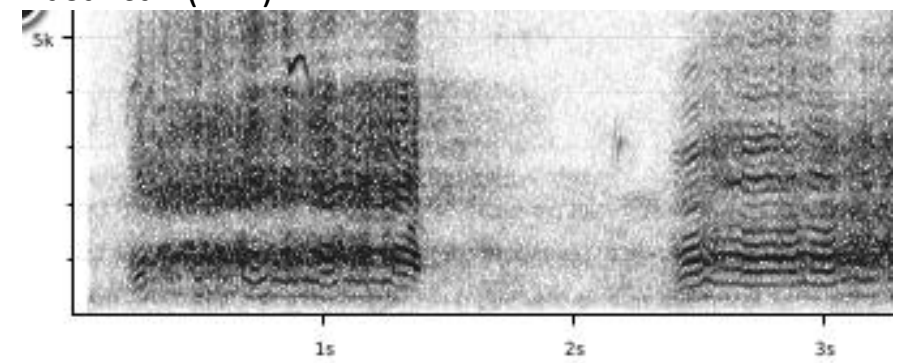

(sonogram from XC103215, Germany, C. Bock)

Short "kok" call ( $n=2)$

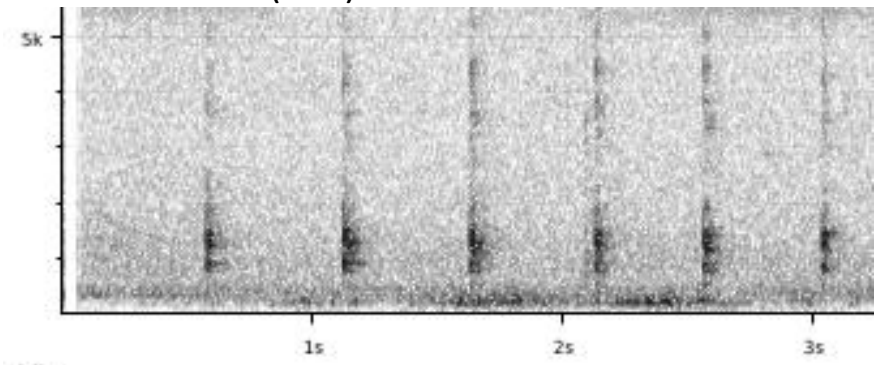

(sonogram from XC340208, Japan, A. Torimi) 


\section{HANDBOOK OF THE \\ Birof Alve}

\section{ORNITHOLOGICAL NOTES}

$\underline{\text { modesta }}$

Rattle call $(n=14)$
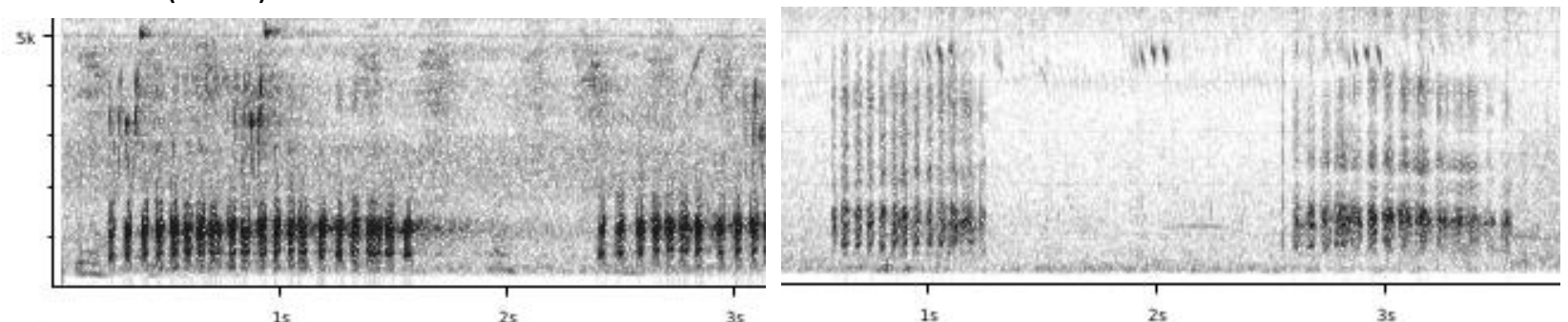

(sonograms from XC173128, Malaysia, F. Lambert; XC149600, India, F. Lambert)

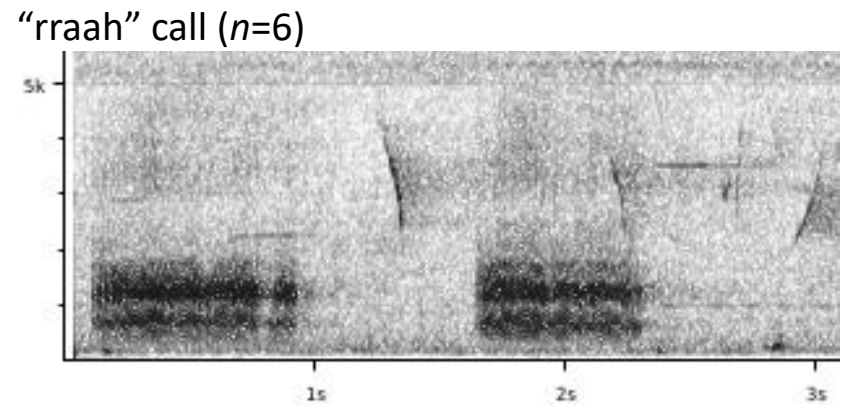

(sonogram from XC173127, Malaysia, F. Lambert)

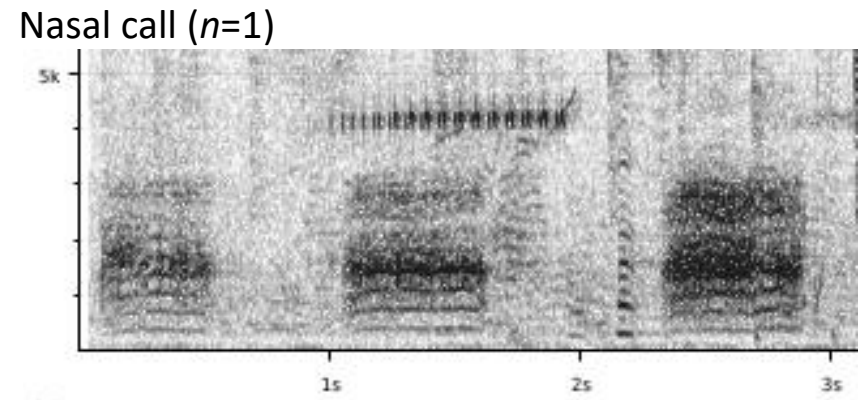

(sonogram from XC116545, India, M. Nelson)

Short "kok" call $(n=1)$

$\underline{\text { melanorhynchos }}$

Rattle call $(n=4)$
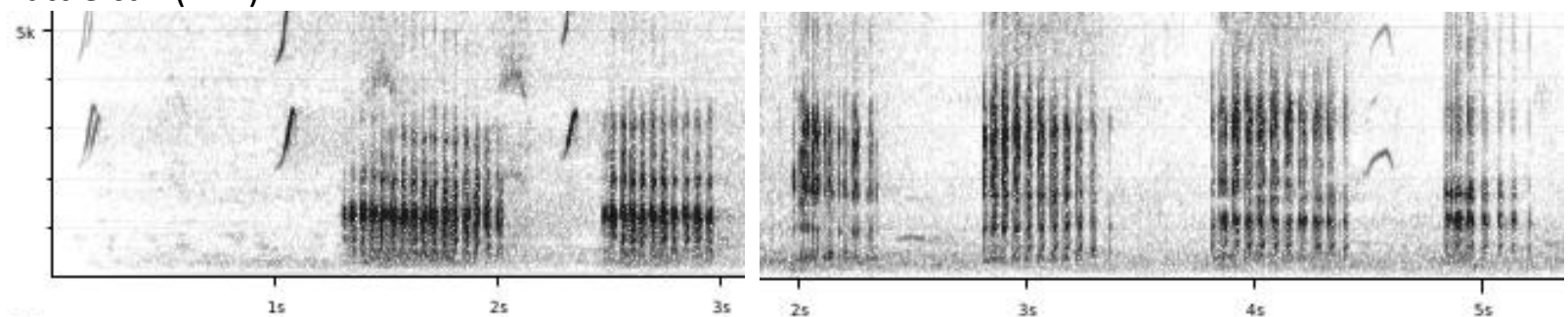

(sonograms from XC307188, South Africa, F. Peacock; XC299961, Ethiopia, P. Boesman) 


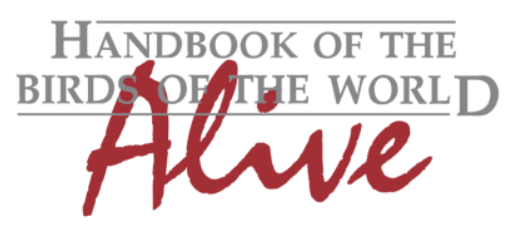

\section{ORNITHOLOGICAL NOTES}

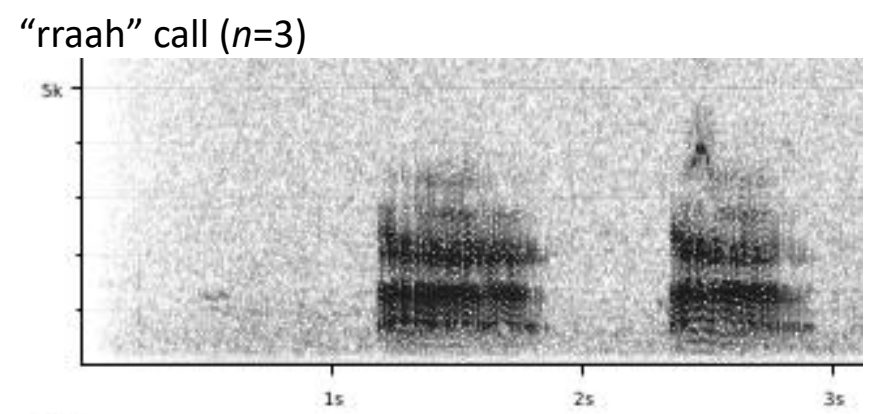

(sonogram from XC307186, South Africa, F. Peacock)

Nasal call $(n=0)$

Short "kok" call $(n=0)$

\section{egretta}

Rattle call $(n=0)$

"rraah" call $(n=41)$

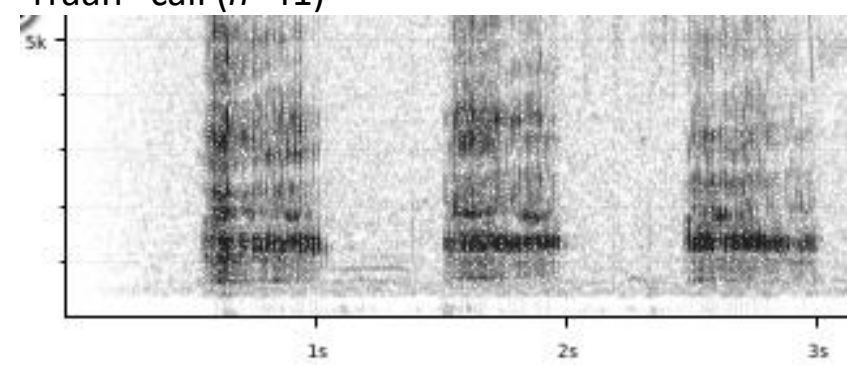

(sonogram from XC50317, Argentina, M. Roda)

Nasal call $(n=23)$
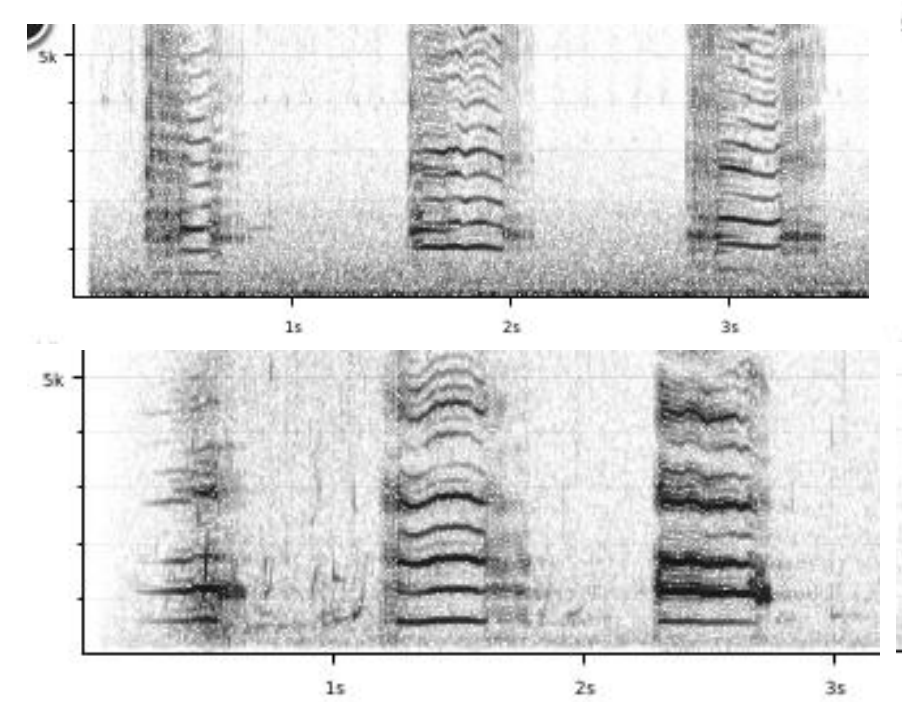
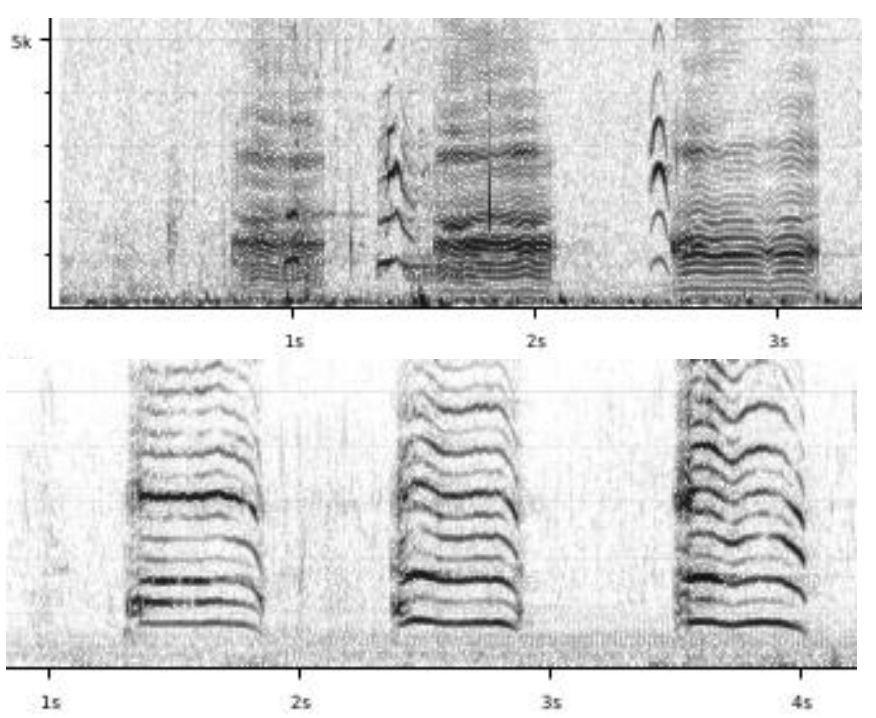

(sonograms from XC290050, Mexico, M. Grosselet; XC361135, Argentina, N. Krabbe; XC50320, Argentina, M. Roda; XC257310, Ecuador, J.V. Moore)

Short "kok" call $(n=5)$ 

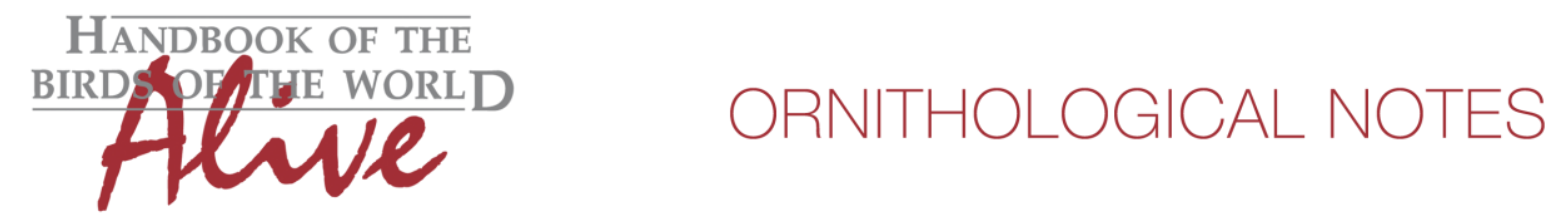

Summarized in the following table, the differences are quite clear:

$\begin{array}{ccccc} & \text { nominate } & \text { modesta } & \text { melanorhynchos } & \text { egretta } \\ & \mathrm{n}=33 & \mathrm{n}=22 & \mathrm{n}=7 & \mathrm{n}=69 \\ \text { Rattle call } & 82 \% & 64 \% & 57 \% & 0 \% \\ \text { "rraah" call } & 9 \% & 27 \% & 43 \% & 59 \% \\ \text { Nasal call } & 3 \% & 5 \% & 0 \% & 33 \% \\ \text { "kok" call } & 6 \% & 5 \% & 0 \% & 7 \%\end{array}$

Subspecies egretta apparently doesn't utter the rattle call, which is the commonest call in Old World races (or it is uttered so fast that it looks identical to the "rraah" call). The vocabulary of egretta consists mainly of the "rraah" call and the nasal call. While these two call types are also uttered by Old World races, especially the nasal call is rather an exception, and never reaches the extreme nasal rendering of egretta (see above sonograms). There is thus a clear difference in vocalizations. (The total absence of a homologous call could be given a score of 4 using Tobias criteria for the largest possible difference, or alternatively pace of the "commonest call" for egretta could be compared with other races, also leading to a score of 3-4).

Differences among the Old World races are less obvious, and a more detailed analysis with more samples is required. It would seem, however, that modesta has a rattle call that is clearly lower-pitched with energy packed in the lower frequencies, unlike the nominate which is noticeably higher-pitched (estimated score 2). Race melanorhynchos may be intermediate, but recordings of this taxon are too few to draw any conclusions. Similar differences may be true in respect of the "rraah" call.

I conclude that the voice of egretta especially stands apart, while other races show smaller differences, which may nevertheless be statistically significant. This not only offers further support to the conclusion offered by Pratt (2011), who stated that egretta is the most distinctive taxon, but it also adds another clear distinguishing feature to the list of differences shown by this race.

This note was finalized on 5 September 2017, using sound recordings available online at that time. I thank, in particular, the many sound recordists who made their recordings of the species available on $\mathrm{XC}$ and Guy Kirwan for revising the original text.

\section{References}

Christidis, L. \& Boles, W.E. (2008). Systematics and Taxonomy of Australian Birds. CSIRO Publishing, Collingwood, Victoria, Australia.

Kushlan, J. A. \& Hancock, J.A. (2005). The Herons. Oxford University Press, Oxford, U.K. Martínez-Vilalta, A., Motis, A. \& Kirwan, G.M. (2017). Great White Egret (Ardea alba). In: del Hoyo, J., Elliott, A., Sargatal, J., Christie, D.A. \& de Juana, E. (eds.). Handbook of the Birds of the World Alive. Lynx Edicions, Barcelona. (retrieved from http://www.hbw.com/node/52684 on 4 September 2017). Pratt, H.D. (2011). Observations on species limits in the Great Egret (Ardea alba) complex. J. Heron Biol. \& Conserv. 1 (5): 1-5.

Tobias, J.A., Seddon, N., Spottiswoode, C.N., Pilgrim, J.D., Fishpool, L.D.C. \& Collar, N.J. (2010) Quantitative criteria for species delimitation. Ibis 152(4): 724-746. 


\section{HANDBOOK OF THE \\ wionfther \\ Alve}

\section{ORNITHOLOGICAL NOTES}

\section{Recommended citation}

Boesman, P. (2016). Notes on the vocalizations of Great Egret (Ardea alba). HBW Alive Ornithological Note 453. In: Handbook of the Birds of the World Alive. Lynx Edicions, Barcelona. (retrieved from http://www.hbw.com/node/xxxx on 5 September 2017). 